\title{
BMJ Open Cost-effectiveness of a nurse-led internet-based vascular risk factor management programme: economic evaluation alongside a randomised controlled clinical trial
}

\author{
J P Greving, ${ }^{1}$ H A H Kaasjager, ${ }^{2}$ J W P Vernooij, ${ }^{3}$ M M C Hovens, ${ }^{2} \mathrm{~J}$ Wierdsma, ${ }^{3}$ \\ H M H Grandjean, ${ }^{2}$ Y van der Graaf, ${ }^{1} \mathrm{G} A$ de Wit, ${ }^{1,4} \mathrm{~F}$ L J Visseren ${ }^{3}$
}

To cite: Greving JP, Kaasjager $\mathrm{HAH}$,

Vernooij JWP, et al. Costeffectiveness of a nurse-led internet-based vascular risk factor management programme: economic evaluation alongside a randomised controlled clinical trial. BMJ Open 2015;5: e007128. doi:10.1136/ bmjopen-2014-007128

- Prepublication history for this paper is available online. To view these files please visit the journal online (http://dx.doi.org/10.1136/ bmjopen-2014-007128).

Received 6 November 2014 Revised 20 February 2015 Accepted 26 February 2015

CrossMark

For numbered affiliations see end of article.

Correspondence to Prof Dr Frank L J Visseren; F.L.J.Visseren@umcutrecht.nl

\section{ABSTRACT}

Objective: To assess the cost-effectiveness of an internet-based, nurse-led vascular risk factor management programme in addition to usual care compared with usual care alone in patients with a clinical manifestation of a vascular disease.

Design: Cost-effectiveness analysis alongside a randomised controlled trial (the Internet-based vascular Risk factor Intervention and Self-management (IRIS) study).

Setting: Multicentre trial in a secondary and tertiary healthcare setting.

Participants: 330 patients with a recent clinical manifestation of atherosclerosis in the coronary, cerebral, or peripheral arteries and with $\geq 2$ treatable vascular risk factors not at goal.

Intervention: The intervention consisted of a personalised website with an overview and actual status of patients' vascular risk factors, and mail communication with a nurse practitioner via the website for 12 months. The intervention combined selfmanagement support, monitoring of disease control and pharmacotherapy.

Main outcome measures: Societal costs, qualityadjusted life-years (QALYs) and incremental costeffectiveness.

Results: Patients experienced equal health benefits, that is, 0.86 vs 0.85 QALY (intervention vs usual care) at 1 year. Adjusting for baseline differences, the incremental QALY difference was $-0.014(95 \% \mathrm{Cl}$ -0.034 to 0.007$)$. The intervention was associated with lower total costs ( $€ 4859$ vs $€ 5078$, difference $€ 219,95 \% \mathrm{Cl}-€ 2301$ to $€ 1825)$. The probability that the intervention is cost-effective at a threshold value of $€ 20000 / Q A L Y$, is $65 \%$. At mean annual cost of $€ 220$ per patient, the intervention is relatively cheap.

Conclusions: An internet-based, nurse-led intervention in addition to usual care to improve vascular risk factors in patients with a clinical manifestation of a vascular disease does not result in a QALY gain at 1 year, but has a small effect on vascular risk factors and is associated with lower costs.

\section{Strengths and limitations of this study}

- This economic evaluation is alongside the largest, randomised controlled clinical trial on internet-based, nurse-led treatment of patients with vascular disease to date.

- This intervention is quite inexpensive, as it was internet based.

- The effect was small and on a surrogate outcome (Framingham risk profile).

- This intervention does not result in a qualityadjusted life-year gain at 1 year.

Trial registration number: NCT00785031.

\section{INTRODUCTION}

Patients with a recent clinical manifestation of a vascular disease (eg, myocardial infarction, stroke, peripheral arterial disease) are at increased risk for developing a new vascular event or death. ${ }^{1}$ Nowadays, more patients survive an acute vascular event and as a consequence the total number of patients in the chronic phase of vascular disease is increasing. Established strategies to reduce vascular risk are to treat hypertension, to lower lowdensity lipoprotein (LDL) cholesterol, to use platelet inhibitors, to control weight, to stop smoking and to increase physical activity. ${ }^{2-5}$ Treatment of these risk factors, alone or in combination, has proven to be very effective in reducing the risk of recurrent vascular events (myocardial infarction, ischaemic stroke) and death. ${ }^{6}$ However, in daily clinical practice, treatment goals are often not reached. ${ }^{78}$ Treatment of vascular risk factors 
by nurse practitioners has proven to be effective in reducing cardiovascular risk factors and vascular risk. ${ }^{9}$ Recently, we provided evidence that an internet-based, nurse-led treatment programme in addition to usual care for vascular risk factors had a small effect on lowering vascular risk and on lowering of some vascular risk factors in patients with vascular disease. ${ }^{10}$

To date, the cost-effectiveness of internet-based interventions has been shown in a low vascular risk population, ${ }^{11}{ }^{12}$ in diabetes management ${ }^{13}$ and in secondary prevention of heart disease. ${ }^{14}$ However, the interpretation of the results and the generalisability of these studies is hampered by a short duration of the intervention or by a highly selected population. Evidence that patient portals improve health outcomes, costs or healthcare utilisation is insufficient. ${ }^{15}$

We therefore carried out an economic evaluation alongside our multicentre, randomised trial, the Internet-based vascular Risk factor Intervention and Self-management (IRIS) study, to investigate the cost-effectiveness.

\section{METHODS}

\section{Study design and patients}

A detailed description of the design and intervention of the IRIS study can be found elsewhere. ${ }^{10}$ Briefly, the trial was a multicentre randomised clinical trial. Patients diagnosed with a recent clinical manifestation of atherosclerosis in the coronary, cerebral or peripheral arteries underwent a standardised vascular risk screening programme. Consenting patients aged $18-80$ years with $\geq 2$ treatable vascular risk factors not at target were included and were randomised to usual care or an internet-based, nurse-led vascular risk management programme in addition to usual care. Randomisation was carried out using block randomisation with a block size of 10 stratified per centre and an online randomisation procedure with a printed confirmation. The study excluded patients who were dependent in personal activities of daily living, patients unable to read and write Dutch, patients without internet access at home and patients with a life expectancy $<2$ years or with a malignant disease.

\section{Internet-based nurse-led risk factor programme and usual care}

At the start of the internet-based, nurse-led vascular risk factor management programme, patients were invited for a visit to the outpatient clinic of the nurse practitioner in the hospital. At this visit, patients received information on their vascular risk factor levels, were instructed about the internet programme and received a username and password. Subsequent contacts between patient and nurse practitioner were through the internet and no further outpatient clinic visits were scheduled. Depending on the presence of risk factors that needed (additional) treatment, the nurse practitioner personalised the website for each individual patient. The opening page showed an overview of the actual status of all risk factors (green=at goal, yellow=close to goal, red=needs attention) and drug use. Within the personalised website, each risk factor was displayed on a separate internet page containing a history of risk factor measurements (such as blood pressure or LDL cholesterol), drug use, treatment goal, advice from the nurse, correspondence between nurse and patient, and news items for that particular risk factor. Patients were instructed to use the website as frequently as considered convenient and necessary at their own discretion, and to $\log$ in at least every other week to submit new measurements (blood pressure, weight, smoking status, cholesterol) and to read and send messages. The nurse practitioner was able to view all files and pages from all patients, and had an overview of the current status of risk factors, last log-in attempts of each patient and new messages sent by patients. In general, the nurse practitioner logged-in every working day and replied to messages sent by patients, and sent messages to patients not actively using the programme at least every other week. The care delivered by the nurse practitioner conducting the internet programme was in addition to usual care and therefore did not replace the care given by the treating physician in the hospital or by the general practitioner.

Patients randomised to usual care were stimulated to contact their treating physician in the hospital (vascular surgeon, cardiologist, neurologist) and/or the general practitioner, for risk factor management. The usual care given by medical specialist and/or general practitioner was also based on the Dutch cardiovascular risk management guideline. ${ }^{16}$ The treating physician was free to determine the frequency of control. This could range from an annual visit for a patient with stable coronary artery disease to every 3 months for patients with type 2 diabetes mellitus.

\section{Resource use}

We collected data on the use of resources at the level of individual patients for 1 year. In a diary, patients recorded the frequency of visits to the medical specialist, nurse practitioner, general practitioner, paramedics or complementary medicine. Questionnaires were completed five times, at baseline and at 3, 6, 9 and 12 months. Furthermore, hospital admission and use of medications was recorded through electronic patient files. Complete data on costs of consultations and inpatient hospital days were available for $85-89 \%$ of the patients. Missing values were imputed with the group mean for that particular cost item. In order to record patients' absence from work, reduced productivity while at paid work, unpaid labour production, and impediments for paid and unpaid labour, patients completed the Short-Form Health and Labour Questionnaire (SF-HLQ) at baseline and at 6 and 12 months. ${ }^{17} 18$ Complete data on costs of work absence and lost productivity were available for 91-92\% of the patients. Missing values were imputed with the group mean for that particular cost item. 


\section{Costs}

Table 1 shows the various types of resources and their unit costs. All costs were assessed from the societal perspective and were calculated per patient by multiplying the volume of resource use by the unit costs. Unit costs were taken from the Dutch manual for costing research in economic evaluations, issued by the Dutch healthcare insurance board (College voor Zorgverzekeringen, CVZ). ${ }^{19}$ Costs were estimated for the year 2009. As the study had a timeframe of 1 year, discounting was not applied.

Medication use of patients was divided into different classes of medication (platelet aggregation inhibitors, lipid-lowering medication, blood pressure-lowering medication and glucose-lowering medication). Costs of vascular medication were valued by calculating a weighted mean of different classes of medication based on aggregate medication use in the Netherlands in 2009 (The Drug Information System of the Health Care Insurance Board $^{20}$ ) and medication price (Z-index taxe November $\left.2009^{21}\right)$. The costs of the internet-based vascular management programme mainly consisted of staff involvement. The programme was managed by specialised nurse practitioners. All nurse practitioners in the programme were asked to keep diaries on the time they spent on managing the patients in the intervention group. Over the year of the intervention, the total number of patient contacts for 11 nurses involved was related to total time spent on the intervention. Hence, average time spent per patient (in minutes per month) in the intervention arm was estimated. This was valued following recommendations from the Dutch costing manual, but it was assumed that nurse practitioners, being highly specialised and well-educated, receive a higher compensation $(€ 33.50 / \mathrm{h})$ than other nurses (€30.50/h).

Direct non-medical costs were estimated using the average transportation costs from the Dutch costing manual. Indirect non-medical costs resulting from paid productivity losses (absence from work and reduced productivity while at work) were calculated by applying mean hourly productivity costs varying with age and sex (data from Statistics Netherlands) and using the friction cost approach. ${ }^{22}$ Costs resulting from unpaid productivity losses were calculated by applying the hourly wage for home support workers $(€ 12.50 / \mathrm{h})$.

\section{Quality of life}

Quality of life was assessed with the EuroQoL five dimensions (EQ-5D) health questionnaire. ${ }^{23}{ }^{24}$ Complete EQ-5D data were available for 90\% (286) of the patients. We imputed missing utility scores with linear interpolation between the two known values on either side or with last observation carried forward if the last value in series had a missing value.

\section{Data analyses}

Intention-to-treat analyses were conducted based on group allocation, regardless of actual intervention received or adherence to the intervention. Initially, we analysed cost and health benefits separately. We calculated mean total

Table 1 Use of resources by patients with recent clinical manifestation of vascular disease and their unit costs $(€)$

\begin{tabular}{|c|c|c|}
\hline Resource & Unit costs $(€)$ & Source \\
\hline \multicolumn{3}{|l|}{ Consultations } \\
\hline General practitioner & 28 & Costing manual ${ }^{19}$ \\
\hline Complementary medicine practitioner & 28 & $\begin{array}{l}\text { Assumed to be equal to costs } \\
\text { of a general practitioner }\end{array}$ \\
\hline Paramedic healthcare professional ${ }^{*}$ & 30 & Costing manual \\
\hline Specialist & 72 & Costing manual \\
\hline Pharmacy compensation per drug per period & 5.5 & Costing manual \\
\hline \multicolumn{3}{|l|}{ Medication costs per month $\dagger$} \\
\hline Platelet aggregation inhibitor & 4.6 & \\
\hline Lipid-lowering medication & 10.5 & \\
\hline Blood pressure-lowering medication & 7.3 & \\
\hline Glucose-lowering medication & 9.3 & \\
\hline \multicolumn{3}{|l|}{ Inpatient hospital days } \\
\hline University hospital & 575 & Costing manual \\
\hline General hospital & 435 & Costing manual \\
\hline 1-year internet-based vascular risk factor management programme & 220 & $\begin{array}{l}\text { Own costing research based } \\
\text { on time assessment }\end{array}$ \\
\hline Travelling costs (per km) & 0.20 & Costing manual \\
\hline Parking costs, per consultation & 3 & Costing manual \\
\hline Reduced productivity (absence from paid work, per hour) & Individualised $\ddagger$ & Costing manual \\
\hline Absence from unpaid work (per hour) & 12.5 & Costing manual \\
\hline \multicolumn{3}{|c|}{$\begin{array}{l}\text { All unit costs are based on } 2009 \text { prices. } \\
\text { *Weighted mean price of different paramedic healthcare professionals. } \\
\text { †Weighted mean prices based on medication use (Genees- en hulpmiddelen Informatie Project (GIP) database) }{ }^{20} \text { and medication prices } \\
\text { (Z-index taxe November 2009). }{ }^{21} \\
\text { †Depending on sex and age. }\end{array}$} \\
\hline
\end{tabular}


costs (ie, the sum of (in) direct medical costs and (in) direct non-medical costs) and mean quality-adjusted lifeyears (QALYs) for both treatment groups. Confidence intervals around the mean differences in costs and QALYs were estimated using bootstrapping with 1000 replications. The incremental cost-effectiveness ratio (ICER) was estimated by dividing the difference in total costs between the treatment groups by the differences in QALYs at 1 year. To graphically present uncertainty around the costeffectiveness ratio, bootstrapped cost-effect pairs (1000 replications) were plotted on a cost-effectiveness plane. A cost-effectiveness acceptability curve (CEAC) was used to present the probability that the internet-based, nurse-led intervention is cost-effective for a range of willingness-to-pay thresholds. This threshold represents the maximum amount of money society is willing to spend to obtain a unit of health outcome (eg, QALYs). All analyses were performed with SPSS statistics V.18.0.2 (IBM Corp, New York, USA) and Microsoft Office Excel 2003.

\section{RESULTS}

\section{Baseline characteristics}

Patients were recruited between October 2008 and March 2010. A total of 638 patients fulfilling inclusion criteria were invited for participation, of whom 330 patients were randomised (figure 1). Sixteen patients $(5 \%)$ were lost to follow-up. The mean age was 59.9 (SD 8.4 years) and most patients were male $(75 \%$; table 2$)$. All patients had a recent manifestation of vascular disease, most frequently this was coronary artery disease $(49 \%)$. Of the study population, $49 \%$ was employed.

\section{Clinical outcomes}

After 1 year, the absolute difference between the intervention group and usual care group in change in Framingham Heart Risk score ${ }^{25}$ was -2.1 (95\% CI -3.8 to -0.3 ). This relates to a relative decrease of $14 \%(95 \%$ CI $-25 \%$ to $-2 \%$ ) in 10-year risk for coronary heart disease. Of the individual risk factors, a difference between groups was

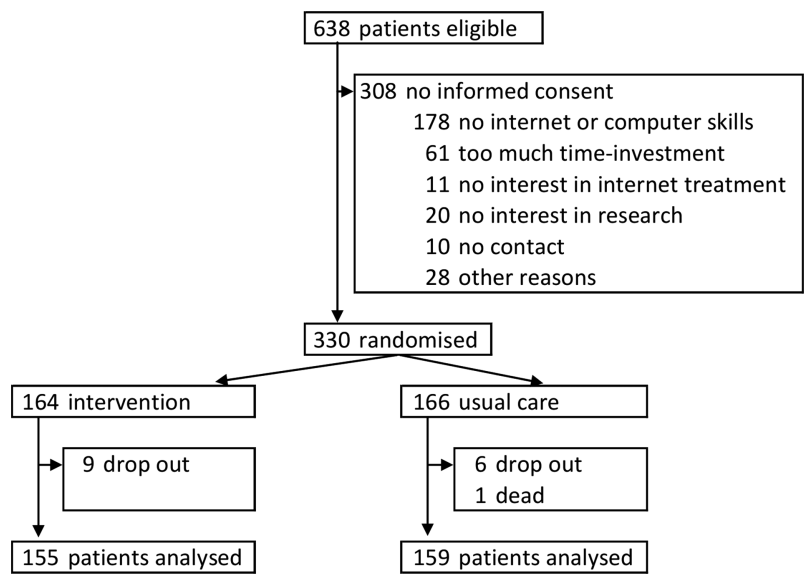

Figure 1 Trial profile.

\begin{tabular}{|c|c|c|}
\hline & $\begin{array}{l}\text { Intervention } \\
(n=164)\end{array}$ & $\begin{array}{l}\text { Usual } \\
\text { care } \\
(n=166)\end{array}$ \\
\hline Age, years & $60.7(7.8)$ & $59.2(8.9)$ \\
\hline Male gender & $128(78)$ & $118(71)$ \\
\hline Body mass index, $\mathrm{kg} / \mathrm{m}^{2}$ & $28.2(4.1)$ & $27.4(3.9)$ \\
\hline \multicolumn{3}{|l|}{ Medical history } \\
\hline Coronary artery disease & $75(46)$ & $69(42)$ \\
\hline Cerebral vascular disease & $44(27)$ & $51(31)$ \\
\hline Abdominal aortic aneurysm & $7(4)$ & $8(5)$ \\
\hline Peripheral vascular disease & $38(23)$ & $38(23)$ \\
\hline Type 2 diabetes mellitus & $43(26)$ & $34(20)$ \\
\hline \multicolumn{3}{|l|}{ Medication use } \\
\hline Platelet aggregation inhibitor & $154(94)$ & $153(92)$ \\
\hline Lipid-lowering medication & $142(87)$ & $140(84)$ \\
\hline $\begin{array}{l}\text { Blood pressure-lowering } \\
\text { medication }\end{array}$ & $130(79)$ & $113(68)$ \\
\hline Glucose-lowering medication & $29(18)$ & $23(14)$ \\
\hline Employment & 77 (49) & 79 (49) \\
\hline Part time job & $19(12)$ & 31 (19) \\
\hline Temporarily unable to work & $10(6)$ & $11(7)$ \\
\hline \multicolumn{3}{|l|}{ Educational level } \\
\hline Lower & $61(39)$ & $74(46)$ \\
\hline Intermediate & $48(31)$ & $42(26)$ \\
\hline Higher & $46(30)$ & $45(28)$ \\
\hline
\end{tabular}

observed in LDL cholesterol $(-0.3 \mathrm{mmol} / \mathrm{L} ; 95 \%$ CI -0.5 to -0.1$)$ and smoking $(-7.7 \% ; 95 \%$ CI $-14.9 \%$ to $-0.4 \%)$.

\section{Quality of life}

Patients in the intervention group experienced 0.86 vs 0.85 QALYs for patients receiving usual care. Adjusting for baseline differences, the incremental QALY difference was $-0.014(95 \%$ CI -0.034 to 0.007$)$, indicating no significant difference in health benefit (table 3 ).

\section{Costs}

Table 4 summarises the mean use of resources by 1 year. The nurse practitioners spent an average of 23 (SD 12) minutes per month per patient on the intervention. Patients in the intervention group appeared to have a similar number of consultations with healthcare professionals and medical specialists compared with the patients in the usual care group. Patients in the intervention group were admitted to hospitals on average 1.4 (SD 4.0) days and patients in the usual care group, 2.6 (SD 10.0) days. Absence from paid work in the intervention group was 132 (SD 263) hours compared with 97 (SD 251) hours in the usual care group (table 4). Total mean costs for both groups are summarised in table 5 . The higher number of inpatient hospital days in the usual care group resulted in higher total direct medical costs (difference of $€ 648$ ) of the usual care group compared with the intervention group. The indirect nonmedical costs were $€ 370$ higher in the intervention 
Table 3 EQ-5D scores at baseline and during follow-up

\begin{tabular}{|c|c|c|c|c|}
\hline & \multicolumn{2}{|l|}{ Intervention } & \multicolumn{2}{|l|}{ Usual care } \\
\hline & Mean (IQR) & Median & Mean (IQR) & Median \\
\hline Baseline & $0.85(0.78-1.00)$ & 0.84 & $0.81(0.77-1.00)$ & 0.81 \\
\hline 3 months & $0.87(0.81-1.00)$ & 0.88 & $0.87(0.78-1.00)$ & 0.89 \\
\hline 6 months & $0.87(0.80-1.00)$ & 0.89 & $0.88(0.78-1.00)$ & 0.90 \\
\hline 9 months & $0.87(0.78-1.00)$ & 0.90 & $0.87(0.78-1.00)$ & 0.90 \\
\hline 12 months & $0.85(0.78-1.00)$ & 0.86 & $0.82(0.78-1.00)$ & 0.84 \\
\hline \multirow[t]{2}{*}{ Total QALYs* } & $0.86(0.78-0.98)$ & 0.89 & $0.85(0.79-0.98)$ & 0.90 \\
\hline & \multicolumn{4}{|c|}{ Mean difference between treatment arms $(95 \% \mathrm{Cl})$} \\
\hline Unadjusted & \multicolumn{4}{|c|}{$0.012(-0.020$ to 0.043$)$} \\
\hline Adjusted $†$ & \multicolumn{4}{|c|}{$-0.014(-0.017$ to 0.041$)$} \\
\hline \multicolumn{5}{|c|}{ Scores of the Dutch value set of the EQ-5D. ${ }^{24}$} \\
\hline
\end{tabular}

group. By 1 year, the overall costs were $€ 4859$ for the intervention group and $€ 5078$ for the usual care group (difference $€ 219,95 \%$ CI $-€ 2301$ to $€ 1825$ ).

\section{Cost-effectiveness analyses}

The cost-effectiveness plane with 1000 bootstrapped costeffect pairs shows a large variation in cost-effectiveness ratios (figure 2A). Figure $2 \mathrm{~B}$ shows the probability that the internet-based, nurse-led intervention is costeffective given a certain threshold value for societal willingness to pay for an extra QALY. Using a threshold value of $€ 20000$ for each QALY gained, there is a $65 \%$ probability that the nurse-led, internet-based intervention is cost-effective. This probability increases at higher threshold levels.

\section{DISCUSSION}

The results of the clinical study indicated that a nurse-led, internet-based vascular risk factor management programme is effective in lowering the Framingham Heart
Risk score in patients with vascular disease by $14 \%(95 \%$ CI $-25 \%$ to $-2 \%) .{ }^{10}$ The present economic evaluation showed that this intervention had equal health benefits and lower costs of $€ 219$ over 1 year, compared with usual care.

In the past decades, many studies attempted to assess the costs and cost-effectiveness of nurse-led vascular risk management interventions. A randomised controlled trial evaluating the effects of a 1-year nurse-led secondary prevention clinic in primary care for patients with coronary heart disease with a follow-up of 4 years $(n=1343)$, revealed that the costs of the intervention were $£ 136 \quad(€ 169)$ with costs per QALY of $£ 1097$ $(€ 1360) .^{26}$ This study was some years ago (1994-1995) and did not use internet, which influences the costs and cost-effectiveness. In another randomised controlled study, evaluating the cost-effectiveness of a web-based primary prevention programme targeted at medical and behavioural risk factors, the incremental cost was $€ 433$ and the incremental effectiveness was 0.016 QALYs after 1 year. $^{11}$ The ICER was $€ 26910$ per QALY. In a

Table 4 Use of resources during 1 year follow-up

\begin{tabular}{lcc} 
& & Usual care \\
\hline Consultations, number per year & Intervention & $5.1(4.6)$ \\
General practitioner & & $0.2(1.2)$ \\
Complementary medicine practitioner & $5.4(5.2)$ & $9.8(17.9)$ \\
Paramedic healthcare professional & $0.5(2.5)$ & $4.6(4.8)$ \\
Specialist & $6.4(4.4)$ & $4.9(5.8)$ \\
Inpatient hospital, days per year & & $1.6(7.8)$ \\
University hospital & $0.4(1.7)$ & $1.1(4.4)$ \\
General hospital & $1.0(3.6)$ & $5.0(2.4)$ \\
Number of different drugs used & $5.4(2.6)$ & $97(251)$ \\
Loss of productivity, hour/year & & $31(93)$ \\
Absence from paid work & $132(263)$ & $13(47)$ \\
Reduced productivity while at paid work & $20(91)$ & - \\
Absence from unpaid work & $13(37)$ & $23(12)$ \\
Time spent by nurse practitioner, min/month & & \\
\hline Values are means (SDs). &
\end{tabular}


Table 5 Cumulative mean costs $(€)$ for patients with a recent manifestation of vascular disease during trial

\begin{tabular}{|c|c|c|c|c|}
\hline \multirow{2}{*}{ Medical costs } & \multirow[t]{2}{*}{ Intervention } & \multirow[t]{2}{*}{ Usual care } & \multicolumn{2}{|c|}{ Difference $(95 \% \mathrm{Cl})$} \\
\hline \multirow{2}{*}{\multicolumn{5}{|c|}{ Consultation }} \\
\hline & & & & \\
\hline General practitioner & 151 & 142 & 9 & \\
\hline Complementary medicine practitioner & 13 & 6 & 7 & \\
\hline Paramedic healthcare professional & 192 & 294 & -102 & \\
\hline Specialist & 353 & 333 & 20 & \\
\hline \multicolumn{5}{|l|}{ Inpatient hospital days } \\
\hline University hospital & 249 & 935 & -685 & \\
\hline General hospital & 421 & 462 & -41 & \\
\hline Medication & 451 & 464 & -13 & \\
\hline Internet-based vascular risk factor management programme & 220 & 0 & 220 & \\
\hline Subtotal & 2052 & 2635 & -583 & $(-1682$ to 308$)$ \\
\hline \multicolumn{5}{|l|}{ Direct non-medical costs } \\
\hline \multicolumn{5}{|l|}{ Visits } \\
\hline General practitioner & 1 & 1 & 0 & \\
\hline Complementary medicine practitioner & 0 & 0 & 0 & \\
\hline Paramedic healthcare professional & 3 & 4 & -1 & \\
\hline Specialist & 22 & 20 & 1 & \\
\hline Inpatient hospital & 6 & 12 & -6 & \\
\hline Subtotal & 32 & 38 & -6 & $(-17$ to 6$)$ \\
\hline \multicolumn{5}{|l|}{ Indirect non-medical costs } \\
\hline Absence from paid work & 2289 & 1675 & 614 & \\
\hline Reduced productivity at paid work & 326 & 566 & -240 & \\
\hline Absence from unpaid work & 159 & 164 & -4 & \\
\hline Subtotal & 2775 & 2405 & 370 & $(-1363$ to 2276$)$ \\
\hline Total costs & 4859 & 5078 & -219 & (-2301 to 1825$)$ \\
\hline
\end{tabular}

retrospective, quasi-experimental design, participants in an internet-based diet and exercise programme were analysed for healthcare costs. ${ }^{27}$ Among a subgroup of participants with vascular risk factors, healthcare costs during the study year were on average US\$827 lower compared with non-participants with vascular risk factors. These trials suggest that vascular risk reduction by internet-based care might be cost-effective.

The intervention in our study can easily be implemented in regular care for patients who experienced recurrent vascular events as well, either in secondary care or in primary care. An increasing proportion of patients has access to internet at home and nurse practitioners can relatively easily implement internet-based care in their clinical practice. Implementation costs for software are relatively low. However, to be effective and costeffective, we believe there are some key elements of our internet intervention that need special attention. The internet-based care needs to be tailored to the clinical situation, risk factor levels and personal goals of each individual patient. Personal goal setting is an essential element in a self-management programme. At the start of the study, each patient saw the treating nurse practitioner in person and discussed personal goals and priorities.

A strength of the present study is that the economic evaluation is part of the largest randomised controlled clinical trial on internet-based, nurse-led treatment of patients with vascular disease to date. The drop-out rate was only $5 \%$ and data collection was almost complete. Some study limitations need to be considered too. First, we used the Framingham Heart Risk score to estimate the vascular risk. ${ }^{25}$ Although this vascular risk score is not accurate in estimating the absolute vascular risk in patients with clinical manifest vascular disease, it can be used to evaluate relative differences and changes between groups. Second, as most cost-effectiveness analyses performed alongside clinical trials, our study was not powered to detect a significant difference in costs. Third, we restricted our analysis to actual costs during the intervention period, and disregarded developmental costs and costs for training staff. As these were one-time costs, their impact on the cost of internet-based vascular risk management programme per patient would be very low and is expected to decrease rapidly with time. Another limitation of the clinical trial is that results can be generalised to patients with access to the internet at home and with sufficient computer skills only. Fourth, the burden on patients might be different, but it is unclear if this results in higher or lower burden with the internet-based vascular risk management programme. Portal contacts may replace some real-time contacts, which would reduce patient time investments, such as time spent waiting in the physician's office before an appointment, travel time, etc. Fifth, there was no QALY gain between the intervention and usual care at 1 year 
Figure 2 (A) Incremental costs and quality-adjusted life-years (QALYs) for a nurse-led, internet-based vascular risk factor management programme compared with usual care: cost-effectiveness plane for incremental costs and QALYs at 1 year, with $C E$ threshold line (€20 000/QALY). (B) Costeffectiveness acceptability curve showing the probability that a nurse-led, internet-based vascular risk factor management programme is cost-effective compared with usual care over a range of societal willingness-to-pay values.

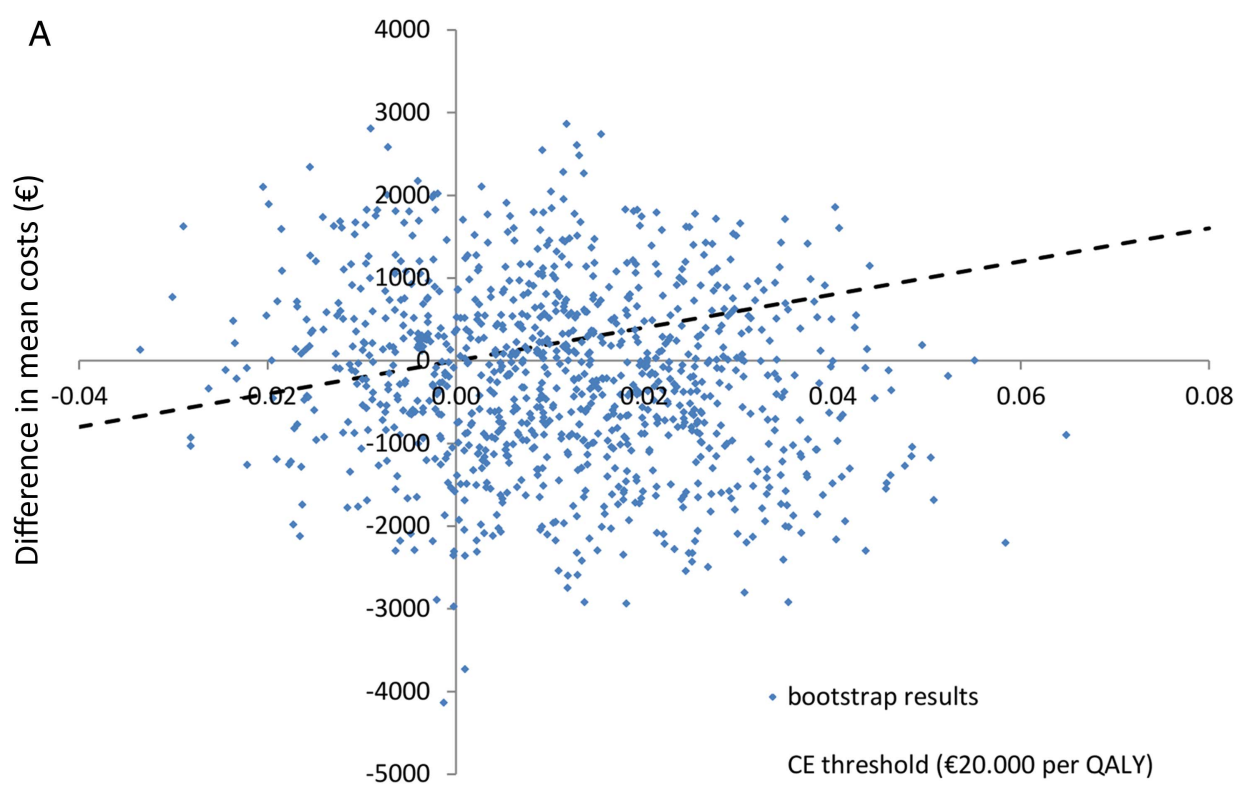

Difference in mean QALYS

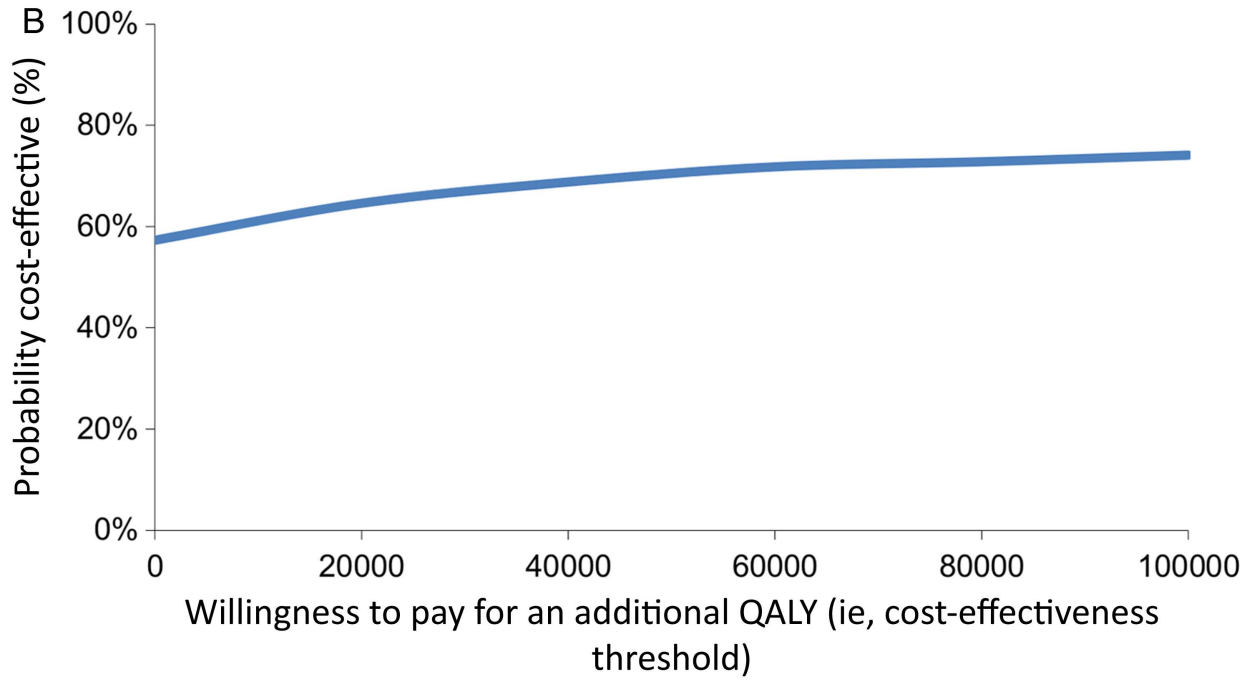

intervention. With bootstrapping, we accounted for the uncertainty surrounding the estimation and showed that the intervention had a probability of $65 \%$ to be costeffective compared with usual care (at a €20 000/QALY threshold value).

In conclusion, an internet-based, nurse-led vascular risk programme in addition to usual care to improve vascular risk factors in patients with a recent clinical manifestation of vascular disease does not result in a QALY gain at 1 year, but has a small effect on vascular risk factors and is associated with lower costs.

\footnotetext{
Author affiliations

${ }^{1}$ Julius Center for Health Sciences and Primary Care, University Medical Center Utrecht, Utrecht, The Netherlands

${ }^{2}$ Department of Internal Medicine, Rijnstate Hospital, Arnhem, The Netherlands

${ }^{3}$ Department of Vascular Medicine, University Medical Center Utrecht, Utrecht, The Netherlands
}

${ }^{4}$ National Institute of Public Health and the Environment, Bilthoven, The Netherlands

Acknowledgements The authors gratefully acknowledge the work of the nurse practitioners $S$ Roos, $R$ van de Meijden, M Seger, D van Koten, $L$ Lensen, A Punt, S Hickox, B Sol and D de Bie; the research nurses C Joosten and I Klaassen; the data manager $R$ van Petersen; and of $A$ Geerts and $J$ Maaskant, who built the website. They also gratefully acknowledge the members of the SMART Study Group of UMC Utrecht: A Algra, MD, PhD, Julius Center for Health Sciences and Primary Care and Department of Neurology; PA Doevendans, MD, PhD, Department of Cardiology; $Y$ van der Graaf, MD, PhD, DE Grobbee, MD, PhD and GEHM Rutten, MD, PhD, Julius Center for Health Sciences and Primary Care; LJ Kappelle, MD, PhD, Department of Neurology; WPThM Mali, MD, PhD, Department of Radiology; FL Moll, MD, PhD, Department of Vascular Surgery; and FLJ Visseren, MD, $\mathrm{PhD}$, Department of Vascular Medicine.

Contributors All the authors participated in the design and conduct of the trial. FLJV was the primary investigator together with YvdG and HAHK. FLJV YvdG and HAHK wrote the study protocol. HAHK, JW, HMHG, MMCH and JWPV contributed to informing potential study patients and providing care for patients during the study. JWPV wrote the first draft of the manuscript. JPG, 
FLJV, YvdG and GAdW provided a thorough revision of the manuscript. FLJV is the guarantor.

Funding This study was financially supported by ZonMw, the Netherlands Organization for Health Research and Development (National Institute for Health Research), grant number 80-00702-98-084.

Competing interests FLJV's department has received grant support from Merck, the Netherlands Organisation for Health Research and Development, and the Catharijne Foundation Utrecht; and FLJV has received speakers' fees from Merck and AstraZeneca. HAHK has received fees for cardiovascular risk management education programmes from non-profit organisations.

Patient consent All participants gave written informed consent.

Ethics approval The study was approved by the medical ethics committee of the University Medical Center Utrecht (Number 08-119/0) and the local medical ethics committee of the Rijnstate Hospital Arnhem.

Provenance and peer review Not commissioned; externally peer reviewed.

Data sharing statement Requests for analyses of de-identified data from this trial should be directed to the corresponding author.

Open Access This is an Open Access article distributed in accordance with the Creative Commons Attribution Non Commercial (CC BY-NC 4.0) license, which permits others to distribute, remix, adapt, build upon this work noncommercially, and license their derivative works on different terms, provided the original work is properly cited and the use is non-commercial. See: http:// creativecommons.org/licenses/by-nc/4.0/

\section{REFERENCES}

1. Kannel WB. Overview of atherosclerosis. Clin Ther 1998;20(Suppl B):B2-17.

2. Antithrombotic Trialists' Collaboration. Collaborative meta-analysis of randomised trials of antiplatelet therapy for prevention of death, myocardial infarction, and stroke in high risk patients. BMJ 2002;324:71-86.

3. Baigent C, Keech A, Kearney PM, et al. Efficacy and safety of cholesterol-lowering treatment: prospective meta-analysis of data from 90,056 participants in 14 randomised trials of statins. Lancet 2005;366:1267-78.

4. Yusuf S, Sleight $P$, Pogue J, et al. Effects of an angiotensinconverting-enzyme inhibitor, ramipril, on cardiovascular events in high-risk patients. The Heart Outcomes Prevention Evaluation Study Investigators. N Engl J Med 2000;342:145-53.

5. Gaede $\mathrm{P}$, Lund-Andersen $\mathrm{H}$, Parving $\mathrm{HH}$, et al. Effect of a multifactorial intervention on mortality in type 2 diabetes. $N$ Engl J Med 2008;358:580-91.

6. Yusuf S, Hawken S, Ounpuu S, et al. Effect of potentially modifiable risk factors associated with myocardial infarction in 52 countries (the INTERHEART study): case-control study. Lancet 2004;364:937-52.

7. Brouwer BG, Visseren FL, Algra A, et al. Effectiveness of a hospital-based vascular screening programme (SMART) for risk factor management in patients with established vascular disease or type 2 diabetes: a parallel-group comparative study. J Intern Med 2010;268:83-93.
8. Kotseva K, Wood D, De Backer G, et al. Cardiovascular prevention guidelines in daily practice: a comparison of EUROASPIRE I, II, and III surveys in eight European countries. Lancet 2009;373:929-40.

9. Goessens BM, Visseren FL, Sol BG, et al. A randomized, controlled trial for risk factor reduction in patients with symptomatic vascular disease: the multidisciplinary Vascular Prevention by Nurses Study (VENUS). Eur J Cardiovasc Prev Rehabil 2006;13:996-1003.

10. Vernooij JW, Kaasjager HA, van der Graaf Y, et al. Internet based vascular risk factor management for patients with clinically manifest vascular disease: randomised controlled trial. BMJ 2012;344:e3750.

11. Jacobs N, Evers S, Ament A, et al. Cost-utility of a cardiovascular prevention program in highly educated adults: intermediate results of a randomized controlled trial. Int $J$ Technol Assess Health Care 2010;26:11-19.

12. Carr LJ, Bartee RT, Dorozynski C, et al. Internet-delivered behavior change program increases physical activity and improves cardiometabolic disease risk factors in sedentary adults: results of a randomized controlled trial. Prev Med 2008;46:431-8.

13. Glasgow RE, Kurz D, King D, et al. Twelve-month outcomes of an internet-based diabetes self-management support program. Patient Educ Couns 2012;87:81-92.

14. Southard BH, Southard DR, Nuckolls J. Clinical trial of an internet-based case management system for secondary prevention of heart disease. J Cardiopulm Rehabil 2003;23:341-8.

15. Goldzweig CL, Orshansky G, Paige NM, et al. Electronic patient portals: evidence on health outcomes, satisfaction, efficiency, and attitudes. A systematic review. Ann Intern Med 2013;159:677-87.

16. Stalman WAB, Scheltens T, Burgers JS, et al. Dutch Guideline Cardiovascular Risk Management 2006. Alphen aan den Rijn, The Netherlands: Van Zuiden Communications B.V., 2006.

17. Hakkaart-van Roijen L. Manual Short Form- Health and Labour Questionnaire. The Netherlands: Institute for Medical Technology Assessment, Erasmus University Rotterdam, 2010.

18. van Roijen L, Essink-Bot ML, Koopmanschap MA et al. Labor and health status in economic evaluation of health care. The Health and Labor Questionnaire. Int J Technol Assess Health Care 1996;12:405-15.

19. Hakkaart-van Roijen L, Tan SS, Bouwmans CAM. Manual for cost research, methods and standard cost prices for economic evaluations in health care. Diemen: National Health Care Institute, 2010.

20. The Drug Information System of National Health Care Institute, The Netherlands. http://www.gipdatabank.nl/

21. Z-Index. http://www.z-index.nl/english

22. Koopmanschap MA, Rutten FF, van Ineveld BM, et al. The friction cost method for measuring indirect costs of disease. $J$ Health Econ 1995;14:171-89.

23. EuroQol-a new facility for the measurement of health-related quality of life. The EuroQol Group. Health Policy 1990;16:199-208.

24. Lamers LM, Stalmeier PF, McDonnell J, et al. Measuring the quality of life in economic evaluations: the Dutch EQ-5D tariff. Ned Tijdschr Geneeskd 2005;149:1574-8.

25. Wilson PW, D'Agostino RB, Levy D, et al. Prediction of coronary heart disease using risk factor categories. Circulation 1998;97:1837-47.

26. Raftery JP, Yao GL, Murchie $P$, et al. Cost effectiveness of nurse led secondary prevention clinics for coronary heart disease in primary care: follow up of a randomised controlled trial. BMJ 2005;330:707.

27. Sacks N, Cabral H, Kazis LE, et al. A web-based nutrition program reduces health care costs in employees with cardiac risk factors: before and after cost analysis. J Med Internet Res 2009;11:e43. 